\title{
Motivating factors of infection control in nurse practice
}

\author{
Diana Platace and Inga Millere
}

Rīga Stradinš University, Latvia

\begin{abstract}
Hospitals in developed countries for more than 170 years have been studying and validating a variety of methods for staff motivation: education at work, distributed leaflets, seminars and lectures, provided the necessary equipment and personal protective equipment as well as surveillance and control provided by the hospital epidemiological service. No less important role nurses play in the motivation of psychological factors, such as attitudes, habits, stress and tolerance. Aim - to explore the motivating factors of infection control in nurse practice. The study used qualitative research method - structured interview $(n=36)$ and a quantitative study - questionnaires $(n=230)$. Questionnaires engaged 98 intensive care nurses and 132 surgical nurses. Results - most of the nurses (62.2\%) regularly improved their knowledge of infection control. Infection control rules in their work regularly used $86.1 \%$ of respondents, while $13.9 \%$ of respondents irregularly applied infection control within the patient care process, posing a threat to their own health as well as to patient's health. Nurses noted several motivating factors for infection control, for example, the importance of the rules in patient care $(94.3 \%)$, availability of infection control rules in the ward $(92.6 \%)$, regular supervision provided by head nurse $(84.8 \%)$, positive attitude of colleagues $(80.4 \%)$, availability of the necessary equipment and personal protective equipment, understandable and simple rules for infection control, sufficient time for infection control in patient care, adequate infection control and surveillance in high risk units, provided by the hospital epidemiological service. The most frequently mentioned reasons for breaking the infection control rules were increased workload and burnout, as well as the lack of understanding of the importance of infection control in patients' health maintenance and inappropriate attitude. Conclusions - the study suggests that in high-risk units there are different motivating factors of infection control, such as the necessary equipment and personal protective equipment, comprehensibility and accessibility of infection control rules, infection control and surveillance provided by the hospital epidemiological service. And at the same time, there are factors that disturb nurses' motivation, such as an increased workload, lack of awareness of infection control in practice and inappropriate attitude.
\end{abstract}

Key words: motivating factors, infection control, nurse.

\section{Introduction}

The increase of nosocomial infections (NI), caused by resistant microorganisms, has nowadays drawn attention to the hospital environment. Regardless of great achievements in medicine, $5-10 \%$ of patients, admitted to the hospital, get infections of various degrees, causing serious economic problems and high mortality rate in all countries of the world 
$[1,2]$. SENIC (Study on the efficacy of nosocomial infection control) has proved that correct and qualitative infection control in the hospital radically decreases the economic costs and increases the quality of the care of hospitalized patients. In addition, taking into account the standards and guidelines in the patient treatment and care, as well as carefully choosing the antibiotics in patient treatment, we can reduce the number of patients affected by nosocomial infection by $30-50 \%$, which results in essential decrease in the number of hospital days and patient lethality. Therefore, in hospitals, more and more attention is paid to such infection control measures as hand hygiene, patients' isolation and threshold precautions, decontamination of objects and equipment, cautious use of antibiotics, as well as decontamination of the environment, which allows medical staff timely to find out and prevent spread of causative agents of an infection. It helps to increase the effectiveness of patient care remarkably and to decrease the treatment costs [3, 4]. However, various factors still exist that may influence it, for example, organisation of infection control in the hospital, nursing workload, material-technical supply, guidelines and documentation of the care, as well as nurses' knowledge and attitude [5-8]. The nurse, as the administrator of health care, plays an essential role in elimination of nosocomial infections related to invasive devices, and infection control is the main precondition for qualitative patient care.

In hospitals in developed countries for more than 170 years a variety of methods for staff motivation have been studied and evaluated: education at work, distributed leaflets, seminars and lectures, provided the necessary equipment and personal protective equipment, as well as surveillance and control provided by the hospital epidemiological service. No less important role in nurses' motivation is played by psychological factors, such as attitudes, habits, stress and tolerance.

At present, the world is revising the educational motivating program that includes 1) scientifically based information on infection control measures (e.g, hand hygiene); 2) indications; 3 ) methods. It actually helps to put into practice the written guidance, as well as the targets and the expected result.

The aim of the research was to explore the motivating factors of infection control in nurse practice. The tasks of the research were to create a questionnaire and a structured interview plan with the aim to find out the motivating factors of infection control in nurse practice, as well as find risk factors of motivation in the high-risk departments, to perform research, to summarize and to analyze results and to make conclusions.

The qualitative research method - structured interview $(n=36)$, used in the research work, included infection control specialists or persons responsible for infection control measures in 10 Latvia's regional multi-profile hospitals, as well as a quantitative study questionnaires $(n=230)$. Questionnaires involved 98 intensive care nurses and 132 surgical nurses in 10 Latvia's regional multi-profile hospitals.

\section{Material and methods}

The research was performed in 10 Latvia's regional multi-profile hospitals, included high-risk units such as the intensive care units (ICUs) and the surgical departments. The study results were acquired by qualitative and quantitative study methods:

1. Survey (nurses in the intensive care departments and surgery departments, $n=230$ ), where was used the authors' devised and approved questionnaire. Validity of the structured questionnaire was determined by internal coordination coefficient of Alpha Kronbah test significance calculation and it was higher than 0.6. In total, 500 questionnaires were distributes, from them only 250 were returned. In the study were included 230 completely filled in and valid questionnaires. 
2. Structured interview was carried out with infection control specialists or persons responsible for infection control measures in the hospital (infection control nurse or epidemiologist, or the chief nurse of the hospital) and with head nurses at high-risk departments in all multi-profile regional hospitals in Latvia $(n=36)$. A structured interview plan, designed and approved by the author was used, which consisted of questions with the aim to find out the motivating factors of infection control in nurse practice, as well as to find out the risk factors of motivation in the high-risk departments. The interview with each of the respondents was realized in a separate room, outside the person's working hours and took on average 45 minutes.

\section{Statistical analysis of the data}

The quantitative and qualitative data analysis, used in the research work, included statistical calculations, making summaries of the obtained data, comparing different information, generalizing the obtained results, and analyzing the cause-effect relationship. The data were encoded and entered in the computer programme MS Excel table made. After that the data were converted into the programme SPSS for Windows 16.0 (company SPSS, USA) for the further statistical analysis. The necessary calculations were done in correspondence with the data structure. All nominal scale and categorized parameters were calculated by the absolute and relative frequencies. For comparison of several categorized variables, the transverse table analysis tools were used, like Confidence Interval Analysis (CIA).

\section{Results}

Respondents' work experience in surgery departments and in the intensive care units was from 1 to 49 years, but the mean time was 13.9 years. The answers of the respondents questioned for the number of years after leaving school made up from 0 to 51 years, but the mean number of years for all 230 respondents was 18.2 years.

Most of the nurses $(143 / 230 ; 62.2 \%)$ regularly improved their knowledge in courses, lectures, seminars on infection control and reading relevant literature. 77 respondents $(33.5 \%)$ due to their knowledge of infection control, only once a year attended continuing education courses giving as a reason for lack of motivation lack of interest by the employer. Infection control rules developed in high-risk units in their work regularly used 198 respondents (86.1\%), while $13.9 \%$ (32/230) of respondents irregularly introduced infection control within the patient care process, posing a threat to their own health and to the patient's health. As motivating factors for the implementation of infection control in practice, nurses noted the importance of the rules in patient care $(217 / 230$; 94.3\%), infection control rules in highrisk units $(213 / 230 ; 92.6 \%)$, regular supervision of head nurse in high-risk units (195/230; $84.8 \%)$, example of colleagues and their positive attitude $(185 / 230 ; 80.4 \%)$, the necessary equipment and personal protective equipment (185/230; 80.4\%), understandable and simple rules for infection control $(166 / 230 ; 72.2 \%)$, sufficient time for infection control in patient care $(148 / 230 ; 64.3 \%)$, adequate infection control and monitoring in high-risk units, provided by the hospital epidemiological service $(142 / 239 ; 61.7 \%$ ) (see Fig. 1). The most frequently mentioned reason why the nurses break infection control rules was increased workload and burnout. Most of the nurses' working day lasted for 24 hours.

In the questionnaire, among the suggestions offered by nurses for the improvement of the infection control measures, there was introduction of the guidelines, which are uniform for all Latvian hospitals, introduction of care standard and patient care form, as well as introduction of patient care forms in high risk departments. Nurses also suggested introduction of infection control nurses' position in all regional hospitals, increase in the 


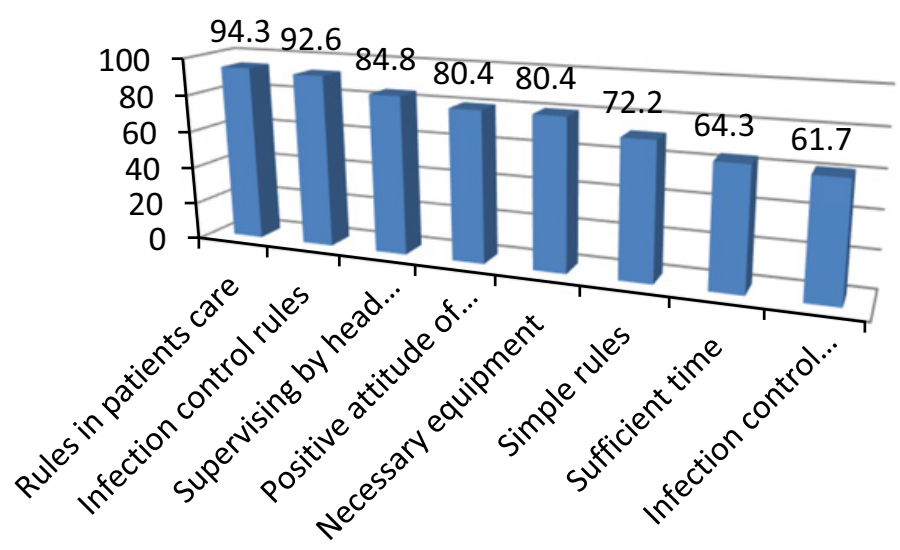

Fig. 1. Motivating factors of infection control in nurse practice.

number of nurses and nurses' assistants for a certain number of patient beds in ICUs and surgical wards, as well as repair-works in wards, especially in those of surgical profile. The responses mentioned are in line with results acquired in the structured interview (see Table 1). 36 respondents from 10 regional multi-profile hospitals participated in the structured interview: $11(30.6 \%)$ respondents - persons responsible for the infection control in the hospital, $10(27.8 \%)$ respondents - head nurses of intensive care units and $15(41.7 \%)$ respondents - head nurses of surgery departments. As seen from the obtained results, which are shown in Table 1, the number of patient beds in 50\% hospitals exceeded 250 and 300 beds, and 50\% hospitals exceeded 500 and 600 beds. Confidence Interval Analysis revealed statistically significant differences $(p<0.05)$ in the following parameters: 1$)$ in ICUs and surgery departments of Latvian regional hospitals (100\%) a unified care documentation for patient care with invasive devices was not established or introduced. An exception was only one hospital in whose department of resuscitation and intensive care there were care documents. During the research, in two hospitals, patient care documents were being worked out; 2) in $90 \%$ of hospitals, starting work in high-risk departments, nurses did not have a chance to undergo training on the infection control; 3) in $90 \%$ of surgery departments and $80 \%$ of ICUs nurses were not regularly provided with the uniform by the employer; 4) in $80 \%$ of surgery departments, nurses were laundering their uniforms at home; 5) in $90 \%$ of surgery departments there was no isolator and, due to financial reasons, in neither of the surgery departments (100\%) there was possibility to provide the nurses' individual station for the care of patients with resistant microorganism infection; 6) safe sharp object collection containers were not available in $88.6 \%$ of high-risk departments; 7) in 90\% of Latvian regional hospitals the recommendations of the USA and European Infection Control Associations on a position of infection control nurse unit per 250 patient beds have not been taken into account; 8) for $90 \%$ of hospital nurses length of the duty in high-risk departments was not limited by 12 hours; 9) in 90\% hospital ICUs under nurse's care were 3, in one case even 4 patients, in neither of surgery departments $(100 \%)$ the number of patients' beds per nurse was limited to $7-8$, only in $13.3 \%$ of surgery departments the number of patient beds per nurse was 10-12.

Results obtained by the questionnaire showed that 43 from 98 (43.9\%) ICUs nurses daily take care of 1 to 5 patients, but 112 from 132 (84.8\%) surgical nurses daily take care of 10-30 patients and even more. Thus, the workload in both ICUs and surgery departments remarkably exceeded the load determined by LR Ministry of Health programme "Cilvēkresursu attīstība veselības aprūpē" ("Development of human resources in healthcare) 


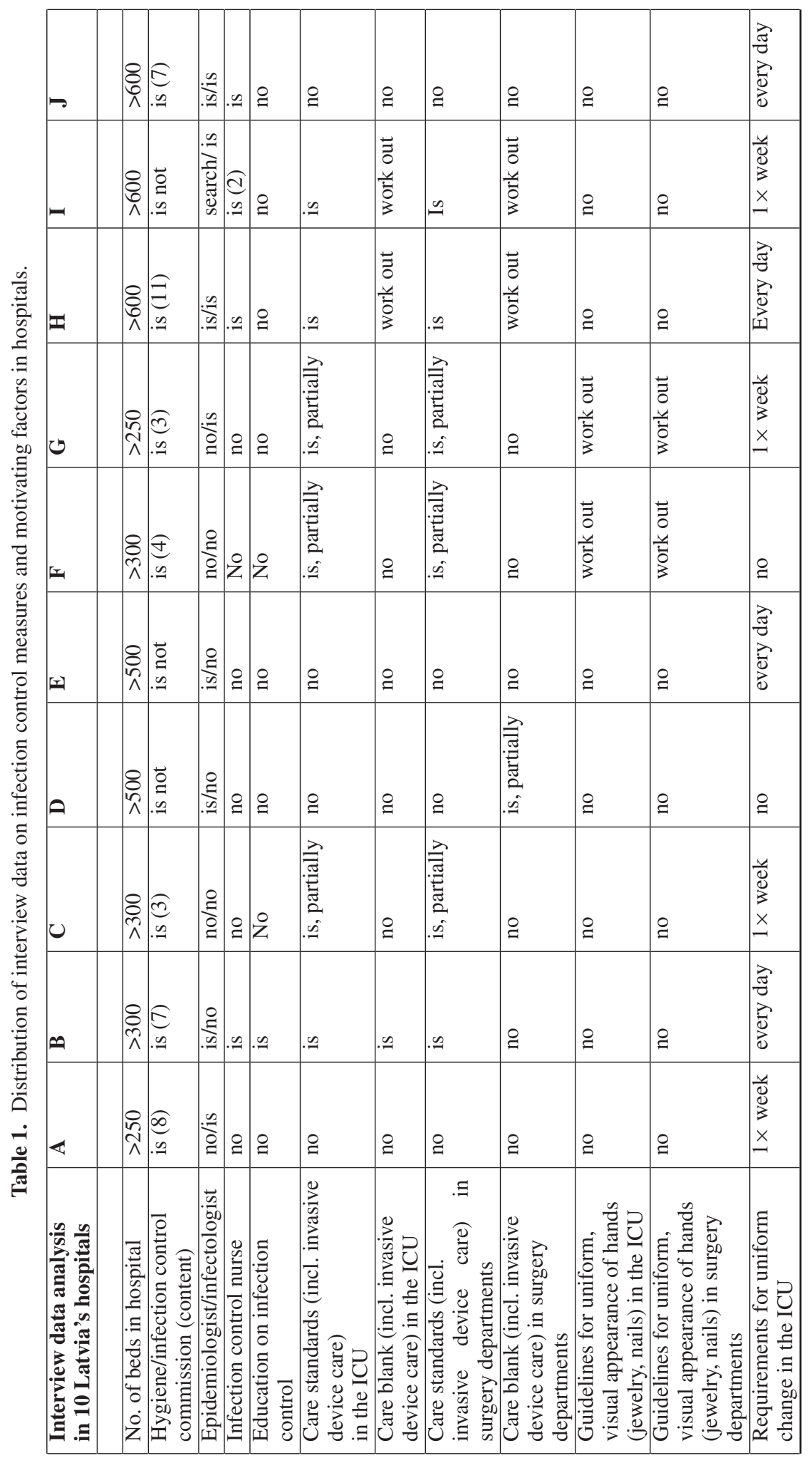




\begin{tabular}{|c|c|c|c|c|c|c|c|c|c|}
\hline$\rightarrow$ & @ & $\cong$ & @ & $\cong$ & @ & $\theta$ & $\stackrel{\bigodot}{9}$ & @ & @ \\
\hline- & 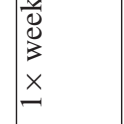 & @ & 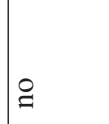 &.$\cong$ &.$\simeq$ & $m$ & $\cong$ & @ & $\cong$ \\
\hline \pm & 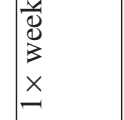 & Ð & @ & $\cong$ & ‡ & $m$ & $\simeq$ & @ & @ \\
\hline ט| & 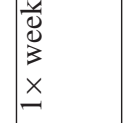 & @ & @ & 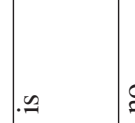 & @ & $m$ & $\stackrel{9}{9}$ & @ & @ \\
\hline Ix & @ & 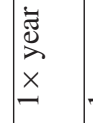 & 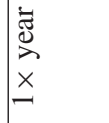 & $\cong$ &.$\simeq$ & $m$ & $\cong$ & $\cong$ & $\cong$ \\
\hline Ix & $\cong$ & 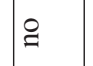 & $\cong$ & 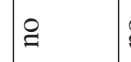 & @ & a & $\stackrel{9}{g}$ & 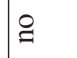 & 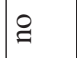 \\
\hline$\theta$ & ‡ & 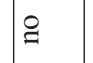 & 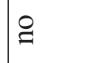 & 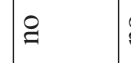 & ‡ & m & 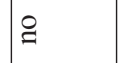 & \& & 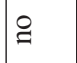 \\
\hline ט & $\begin{array}{l}\underline{y} \\
\bar{D} \\
\underline{z} \\
\underline{x}\end{array}$ & ஜ & 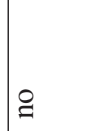 & 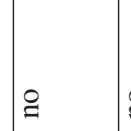 & ‡ & $m$ & @ & @ & @ \\
\hline$\infty$ & 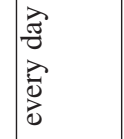 & 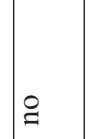 & 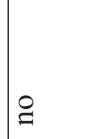 & ஜ & @ & $m$ & 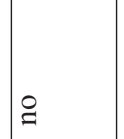 & @ & 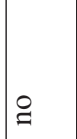 \\
\hline$\ll$ & $\begin{array}{l}y \\
\underline{y} \\
\underline{y} \\
x \\
x\end{array}$ & . & 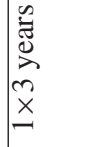 & $\cong$ & $\cong$ & $\mathrm{m}$ & $\Leftrightarrow$ & $\cong$ & 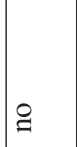 \\
\hline 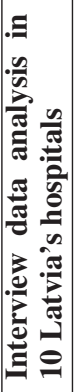 & 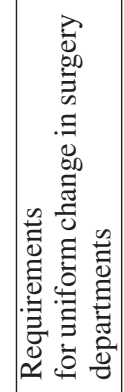 & 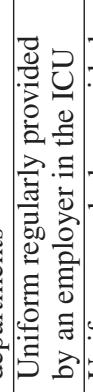 & 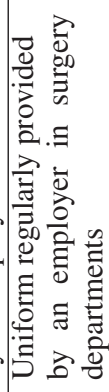 & 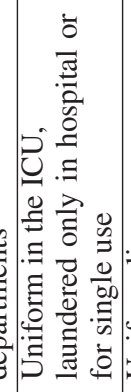 & 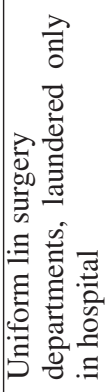 & 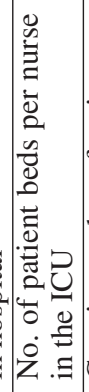 & 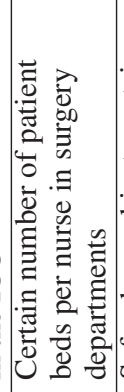 & 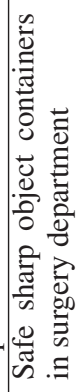 & 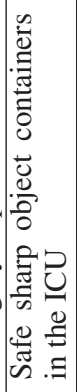 \\
\hline
\end{tabular}


referring to the plan of bed profile (2007-2010) for one nurse's station, which was 2 beds in resuscitation, intensive care department and 8 beds in adult surgery (including purulent) department. It exceeded also criteria given by European Society of Intensive Care Medicine, which envisaged three 1st degree patients in one nurse's care, 1.62 nd care level patients, but one patient of 3rd care level [9].

Thus, the most common recommendations given by nurses for the improvement of the infection control measures on provision of individual safety and equipment safety fully corresponded to the answers of the question for complying or not complying with the rules of the infection control. More than one third of the respondents pointed to the fact, that the necessary equipment and individual protection are available sometimes, or not available at all. In the question on the reasons for not changing the gloves in patient treatment, most of the respondents mentioned the improper washbasin equipment. At the same time, the respondents asserted that the most common reason for not complying with the infection control rules is the lack of knowledge and understanding of the importance of the infection control. For example, "staphylococcus is not seen, therefore no one is scared", "nurses, by wearing gloves, try to protect themselves", and "the gloves are disinfected after each patient's treatment". Some economic reasons were mentioned such as "gloves are disinfected after each patient's treatment or they are not worn at all", as well as the nurses' attitude, which may be negligent ("old habits are more comfortable than the new ones", "attitude depends on the character features"). In addition, improper washbasin equipment was mentioned in $30.9 \%$ cases, lack of gloves or allergy against latex was mentioned respectively by $3.9 \%$ and $26.5 \%$ of respondents. One of the most common nurses' recommendations was related to regular education in the field of the infection control, which shows that nurses understand the need of new knowledge and insufficient skills in the field of the infection control. It is proved by the respondents' answers on hand treatment techniques and methods, on the intravenous infusion therapy, as well as patients' care with urinary catheter, which in most cases was not correct, despite the fact that $62.2 \%$ nurses mentioned that they regularly increase their knowledge on the infection control (1-5 times a year).

\section{Discussion}

Human resources are very important components in health care system and, in order to achieve much better public health indices, it is not enough to have modern technologies or new medicines. According to the author's research, nurses consider that the most common reasons for breaking the rules of the infection control are the following: overload (e.g. "there are cases when a nurse takes care of 40 patients in a ward and 2 MRSA patients", "there are many severely-ill patients, the nurse does not take care of safety, but tries to manage the patient care", "most of nurses have more than 1 workload"). It was confirmed by the study data: in 1 (10\%) of 10 Latvian regional hospitals the number of beds for one nurse's station did not exceed 2 beds in resuscitation and intensive care department, but $90 \%$ - the number of beds for one nurse's station was 3 , in one case even 4 beds in the intensive care unit, while in neither of the surgery departments the number of beds limit to 8 beds, the lowest number of beds stated for the nurse's station in the surgery departments (13.3\%) was 10-12 beds. Thus, we can say that nurses' working load in both ICUs and surgery departments was increased and remarkably exceeded the load determined by the programme of LR Ministry of Health "Cilvēkresursu attīstība veselības aprūpē" (Development of human resources in healthcare) in relation to the bed profile plan (2007-2010). It stated that the scheduled number of beds per one nurse's station meant 2 beds in the intensive care unit and 8 beds in adult surgery (including, purulent) department. The bed profile plan for 2007-2010 was worked out for 
nurses taking general and special care of patients adequately to the set patient care level. It was worked out considering the criteria of European Society of Intensive Care Medicine for the number of patients to be taken care of, taking into account the care level. It envisages three patients of 1 st level care for one nurse, for 2 nd care level - 1.6, but for the 3rd care level one patient [9]. Taking into account that an adequate nurse's load is one of patient's safety and care quality indicators, the programme of LR Ministry of Health "Cilvēkresursu attīstība veselības aprūpe"” (2006-2015) intended to change the care staff's working load, but, due to financial reasons, the prepared bed profile plan for 2007-2020 was not implemented. There are countries in the world, like the USA, where the number of nurses per certain number of patient's beds is regulated by the law. It has been proved that an insufficient number of nurses per certain number of patients essentially affects the increase of unexpected cases, for example, increase of nosocomial infections and patient mortality, while adequate nurse's load decreases the number of unexpected cases from 2-25\%, thus considerably decreasing the medical costs $[6,10]$. In Latvia at present LR “Ārstniecības likums" (Medical Treatment Law) is obligatory and it is in force from October 1, 1997, and it regulates the duties of medical staff. During the recent years, several amendments have been introduced in the law, but they have not described workload and amount of the workload. World Health Organization (WHO) in its report has pointed out that the people are those who are the basis of the health service in the 21 st century, emphasizing that the crisis of human resources in medicine is seen worldwide. Besides, one can see a tendency towards the decrease of the time spent hospital. Thus, in the period from 1980-2000, the mean time spent in hospital has decreased from 7.5 bed days to 4.9 , causing greater care load to nurses because the patient care level is higher. Not only the number of nurses per certain number of patients' beds is included in the nurses' workload, but also monthly workload and length of the duty. The authors' study data showed that in neither of the Latvian regional hospitals the nurses workload in high risk departments was limited for 1 workload per month, but the length of nurses' duties in high risk departments only in 1 from 10 hospitals was limited to 12 hours. AHRQ (Agency for Healthcare Research and Quality) financed the research, which was carried out in 1993 in 10 countries in the world and covered 589 hospitals. It revealed that in the estimates of nurses' workload, adding to the nurse's workload half an hour per 1 patient a day, decreased the morbidity due to pneumonia for surgical patients by $4 \%$. It is an essential financial profit, if we take into account the fact that if pneumonia follows the underlying disease it may increase the patient's treatment costs by 28000 dollars [10-12]. On the other hand, Pittet and co-authors' studies revealed that, due to the staff's big workload, they cannot do proper hygienic hand washing. For a nurse in intensive care ward it makes up to at least 22 episodes per hour, but for the nurse in surgery ward - 17 episodes per hour, comparing to the hand hygienic disinfection with alcohol-containing solution [13].

In many studies it has been proved, that caregiver's hands are the main factors of transmission of nosocomial infections, especially in high-risk patient care [14-19] and there exists a correlation between the improvement of hand hygiene practice and essential decrease of NI [20-22]. Jenner and co-authors in the study revealed that regardless of the fact that hand hygiene does not take much time and resources in high risk departments the compliance of the caregivers in doing hand hygiene did not exceed 40\%. It was explained by such causes as lack of priority to other procedures to be done, lack of time for hand washing, uncomfortable location of washbasins, allergic reactions to washing solutions, lack of supervision of the head of departments and lack of the medical staff [7]. Minnaar (2008), among the reasons, which hinder hand hygiene mentioned the lack of equipment and washbasins, as well as insufficient knowledge and understanding of the importance of hand hygiene from the caregivers [8]. Similar reasons were mentioned by EURIDIKI (European Interdisciplinary Committee for 
Infection Prophylaxis) study, the main being forgetfulness, laziness, lack of knowledge and understanding, lack of time, fright from possible skin reactions, all this affected the caregivers' hand hygiene. According to Pittet and co-authors' study data, health care staff did hand hygiene on average only in the half of all hand hygiene envisaged cases [13].

In the author's research, according to the respondents' opinion, the most common reasons of breaking the rules of the infection control are lack of knowledge and understanding of the significance of the infection control (e.g. "they do not see staphylococci, therefore are not scared", "by wearing gloves, they try to protect themselves, but not the patient, because of long nails, rings", "for economic reasons the gloves are disinfected after each patient's care, or they are not worn at all") and the nurses' possible negligent attitude ("old habits are more comfortable than the new ones", "the attitude depends on the character traits"), as well as insufficient washbasin equipment, which was mentioned in $30.9 \%$ cases. Among other reasons, $3.9 \%$ and $26.5 \%$ respondents respectively had mentioned the lack of gloves or allergy against latex. In $69.6 \%$ of cases, gloves of adequate size and material were available. Comparing to the acquired data of research done in the USA [23] and Poland [24], the adequate size gloves had been available in $49.4-71.1 \%$ of cases in the USA intensive care patients and in $63 \%$ of cases in surgery departments in Poland. It gives evidence of a similar provision with personal protective equipment (individual safety) - gloves in high risk departments in Latvia, USA and Poland, or it also makes us think of modest expectations of nurses in Latvia as to the choice of the size and material of gloves.

In developed country clinics, the experience in the infection control is much greater and it has been acquired for more than 30 years. The identified failures in the organization and provision of the infection control in Latvian hospitals show that Latvia is only at the beginning of the road to the infection control and, at present, the infection control is not a priority in patient care. However, despite the complex economic situation in the country and the lack of experience in the organization of the infection control, we should not forget that the population is not getting healthier and each of the sick has deserved to receive a qualitative and safe care.

\section{Conclusions}

The study suggests that in high-risk units of 10 Latvia's regional multi-profile hospitals there are different motivating factors of infection control, such as the necessary equipment and personal protective equipment, infection control rules comprehensibility and accessibility, infection control and surveillance provided by the hospital epidemiological service. At the same time, there are also factors that disturb nurses' motivation. They are the increased workload, lack of awareness of infection control in practice and inappropriate attitude, as well as lack of unified care documentations for patient care with invasive devices in the intensive care units and surgery departments. Starting work in high risk departments, nurses did not have a chance to undergo training on the infection control.

\section{References}

[1] Y.Y. Chen, F.D. Wang, C.Y. Liu, P. Chou, Infect. Control. Hosp. Epidemiol. 30(1), 39-46 (2009)

[2] S. Dasgupta, S. Das, N.S. Chawan, A. Hazra, Indian J. Crit. Care Med. 19(1), 14-20 (2015)

[3] N.N. Damani, Manual of Infection Control Procedures, 2nd edn. (Greenwich Medical Medial Ltd, London, 2003) 
[4] J. Wilson, Infection Control in Clinical Practice, 3rd edn. (Elsevier, London, 2006)

[5] D. Gould, E. Ream, J. Adv. Nur. 19, 1121-1131 (1994)

[6] S. Hugonnet, J.C. Chevrolet, Crit. Care Med. 35(1), 76-81 (2007)

[7] E.A. Jenner, C. Mackintosh, G.M. Scott, J. Hospital Infect. 42, 91-104 (1999)

[8] A. Minnaar, Infection Control Made Easy: A Hospital Guide for Health Professionals (Professional Nurse Series, Juta and Company Ltd., 2008)

[9] P. Ferdinande, Intensive care Med. 23, 226-232 (1997) Pieejams: http://www.icu.gr/guidelines/920.pdf

[10] M.W. Stanton, M.K. Rutherford, Agency for Healthcare Res. Qual. 14, 1-12 (2004)

[11] S.H. Cho, S. Ketefian, V.H. Barkauskas, et al., Nurs. Res. 52(2), 71-9 (2003)

[12] J. Needleman, P. Buerhaus, S. Mattke, et al., N. Engl. J. Med. 346(22), 1715-22 (2002)

[13] D. Pittet, J.M. Boyce, Lancet Infect. Dis. 4, 9-20 (2001)

[14] B. Allegranzi, D. Pittet, J. Hospital Infect. 73, 305-315 (2009)

[15] J.M. Boyce, D. Pitter, Am. J. Infect. Control. 51(RR - 16), 1-44 (2002)

[16] P. Eggimann, D. Pittet, Infection control in the ICU. Chest 120, 2059-2093 (2002)

[17] J.C. Farmer, Crit. Care Med. 37, 2307-2309 (2009)

[18] S. Kusachi, Y. Sumiyama, Y. Arima, et al., Surg. Today 36(5), 410-415 (2006)

[19] J.P. Marcel, M. Alfa, F. Baquero, J. Etienne, H. Goossens, S. Harbarth, W. Hryniewicz, W. Jarvis, M. Kaku, R. Leclercq, S. Levy, D. Mazel, P. Nercelles, T. Perl, D. Pittet, C. Vandenbroucke-Grauls, N. Woodford, V. Jarlier, Clin. Microbiol. Infect. 14(10), 895-907 (2006)

[20] P.D.R. Johnson, R. Martin, L.J. Burrell, et al., Med. J. Aust. 183, 509-519 (2005)

[21] D. Pittet, Infect. Control Hosp. Epidemiol. 21, 381-386 (2000)

[22] V.D. Rosenthal, S. Guzman, N. Safdar, Am. J. Infect. Control. 33(7), 392-397 (2005)

[23] S.A. Clock, B. Cohen, M. Behta, B. Ross, E.L. Larson, Am. J. Infect. Control 38(2), 105-111 (2010)

[24] M. Ganczak, Z. Szych, J. Hospital Infect. 66, 346-351 (2007) 